Article

\title{
Experimental Tests on a Dowel-Type Timber Connection and Validation of Numerical Models
}

\author{
Fabio Solarino ${ }^{1}$ (D), Linda Giresini ${ }^{1, *}$ (D), Wen-Shao Chang ${ }^{2}$ (D) and Haoyu Huang ${ }^{3}$ \\ 1 Department of Energy, Systems, Territory and Constructions Engineering, University of Pisa, \\ Largo Lucio Lazzarino, 56122 Pisa, Italy; solarino.fabio@gmail.com \\ 2 Sheffield School of Architecture, The University of Sheffield, Sheffield S10 2TN, UK; w.chang@sheffield.ac.uk \\ 3 College of Architecture and Civil Engineering, Beijing University of Technology, \\ 100 Pingleyuan, Beijing 100124, China; huanghaoyu@bjut.edu.cn \\ * Correspondence: linda.giresini@unipi.it
}

Received: 17 October 2017; Accepted: 30 November 2017; Published: 5 December 2017

\begin{abstract}
This paper examines the dynamic behaviour of timber framed buildings under wind and dynamic loads, focusing on the role of connections being experimentally tested. The main aim of this manuscript is to analyze the in-service dynamic behaviour of a semi-rigid moment-resisting dowel-type connection between timber beam and column. For this purpose, two laboratory tests have been performed, the first on a connection and another one on a portal frame. The results are used to validate a numerical model of the simple portal frame, analyzed in OpenSees. The obtained relationships are also discussed and compared with Eurocode rules. The main result is that the joint stiffness is calculated through the Eurocode (EC) formulation underestimates the experimental one. A mutual agreement is obtained between the numerical model, validated from the experimental stiffness value for the connections, and the experimental results on the portal frame.
\end{abstract}

Keywords: timber; dowel-type connection; rotational stiffness; curve fitting; damping; OpenSees

\section{Introduction}

Wind-induced vibrations reveal to be an important design aspect when dealing with timber structures due to their low mass. A deeper knowledge about the connection behaviour is necessary to face this issue. Connections play a significant role on structural stiffness and damping, and the lack of information about their in-service dynamic vibrations challenges designers. The connections in timber structures are often designed by using dowel-type connections and they make a significant contribution to the overall structural stiffness.

Many researchers have experimentally studied dowel type connections, focusing their attention on single dowel connection axially loaded (parallel to the grain direction) [1,2]. Beam-to-column moment resisting dowel type connections have also been tested to achieve a better knowledge about the rotational stiffness of the joint [3-5]. Dynamic properties of dowelled connections have been investigated through cyclic load tests [6,7], showing their contribution to damping in a complete structure. Analytical models can be used to predict in-service stiffness as well as the frictional energy dissipation in embedment [8-12]. Eurocode 5 [13] provides rules for calculating the slip modulus $\left(k_{\mathrm{ser}}\right)$, which can be used to assess the connection stiffness appropriate to static loading under serviceability limit state. Incidentally, the importance of dissipation due to friction has also been analytically and experimentally demonstrated for the collapse failures of masonry structures, by means of a rigid-plastic orthotropic damage model [14-17]. For such structures in a dynamic perspective, the dissipation due to the impact between rigid surfaces also plays an important role $[18,19]$. 
Moreover, the semi-rigid connection stiffness required for modelling and predicting the in-service dynamic behaviour of dowel-type connections is different from the stiffness required for static loading [7]. Furthermore, $k_{\text {ser }}$ is empirically determined, independent of the geometry of the connection, relying only on the diameter of the connector and the timber density. The nonlinearity resulting from ductile connections makes their modelling difficult. Many numerical models have been developed to simulate such a behaviour [20-22] based on the mechanical parameters that play significant roles in the connection. Validation of the model through experimental campaign can be done in order to compare test data to model prediction [23].

This study aims at the evaluation of the in-service stiffness of a beam-to-column moment-resisting $4 \times 4$ dowel-type connection through experimental tests and numerical analysis.

Figure 1 shows the connection that is analyzed in this work. This connection is then included in a $1500 \mathrm{~mm} \times 1500 \mathrm{~mm}$ symmetric portal frame. Localized phenomena (at connection level) are then investigated through a full scale specimen, whereas the global elastic response is simulated at a model scale of 1:2. Indeed, at reduced scales, the prototype response cannot be properly reproduced [24]. For that reason, and to avoid the potentially inaccurate scaling of results, the connection to test have been designed with medium-large connectors (full scale specimen).

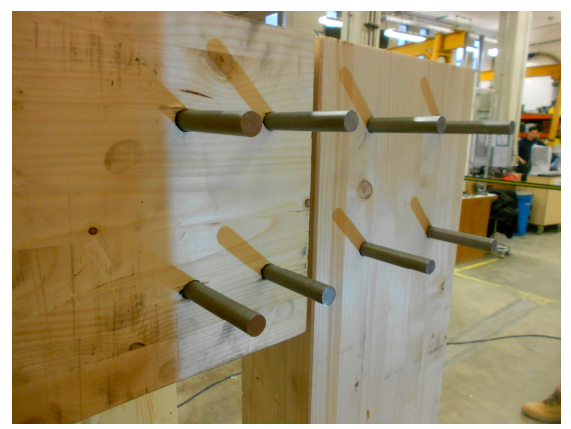

(a)

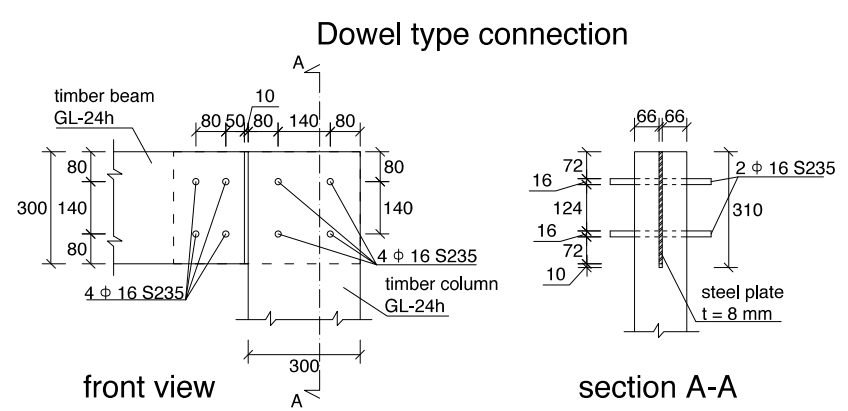

(b)

Figure 1. Dowel type connection: (a) beam-column joint; (b) joint layout (all lengths are in mm).

The single connection is firstly statically tested (Section 2), and its influence on a simple portal frame is estimated with a vibration test (Section 3). Here, the dynamic characteristics of the structure are obtained by means of a MATLAB [25] script based on the Matrix Pencil Algorithm (MP Algorithm) [26]. Experimental results are applied in Section 4 on a three-dimensional (3D) portal frame modelled in OpenSees [27]. Both modal and time-history analysis are performed and results are compared to the experimental outcomes.

\section{Connection Test}

\subsection{Experimental Test Set-Up}

Two experiments were performed in the laboratory at the University of Bath: a static test on a typical steel-timber connection with $4+4$ dowels (Figure $2 a$ ) and a non-destructive vibration test on a symmetric portal frame $1500 \mathrm{~mm} \times 1500 \mathrm{~mm}$ (Figure 2b). The joint was cut off from the frame once the vibration test had been performed.

Each member has cross section of $140 \mathrm{~mm} \times 300 \mathrm{~mm}$ (Figure $2 \mathrm{~b}$ ) and the material is whitewood glulam of grade GL-24h, as defined in EN 1408 [28]. The steel plate slotted in the timber elements links two different connections: a four-dowel connection on the column and a four-dowel connection on the beam. The steel grade is S235, with $8 \mathrm{~mm}$-thick plates and $16 \mathrm{~mm}$ diameter holes accommodating the steel dowels. $16 \mathrm{~mm}$ diameter holes have been drilled into the timber members. The fasteners are of S235 grade and have a diameter of $16 \mathrm{~mm}$ so to fit tight into the holes. Beams and columns were cut with an angle of $45^{\circ}$ and the specimen was vertically loaded so to induce a bending moment in the joint 
(Figure 3a,b). The connection was statically loaded through Instron $2000 \mathrm{kN}$ Universal Testing Machine in displacement-control $(\Delta u=3 \mathrm{~mm} / \mathrm{min})$. Two transducers fixed at the column measured the relative column-beam displacement of the joint in two points spanned $140 \mathrm{~mm}$, placed symmetrically to the beam axes (Figure 2a). The corresponding angular deformation can be easily found through the following equation:

$$
\varphi[\mathrm{rad}]=\tan ^{-1}\left(\frac{\delta_{1}-\delta_{2}}{p}\right),
$$

where $\delta_{1}$ and $\delta_{2}$ are the relative displacements from the two sensors in the direction of the beam axes (Figure $3 \mathrm{c}$ ) and $p$ is the distance between the two reference points $(240 \mathrm{~mm})$. The corresponding moment is evaluated as:

$$
M=F_{\mathrm{y}} \cdot H,
$$

where $F_{\mathrm{y}}=F / \sqrt{2}$ is the component of the force that is applied by the loading machine orthogonal to the axes of the beam and $H=610 \mathrm{~mm}$ is the distance between the loading point and the centroid of the group of dowels of the column side, which is considered as the rotation center of the joint (Figure 3c).

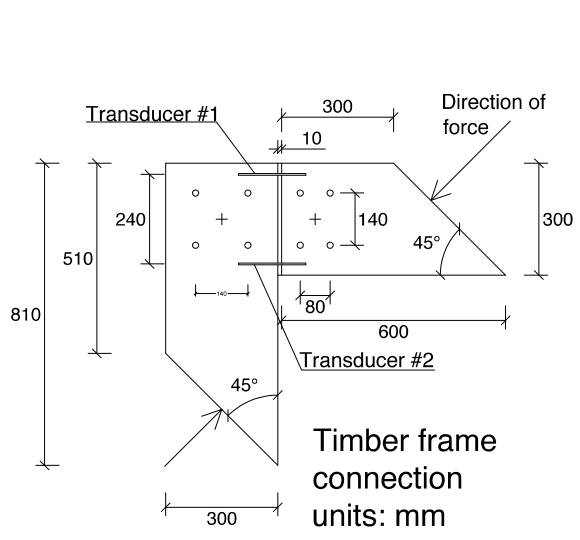

(a)



(b)

Figure 2. Laboratory specimens: (a) steel-timber connection; (b) $1500 \mathrm{~mm} \times 1500 \mathrm{~mm}$ portal frame-all lengths in $\mathrm{mm}$.



(a)



(b)

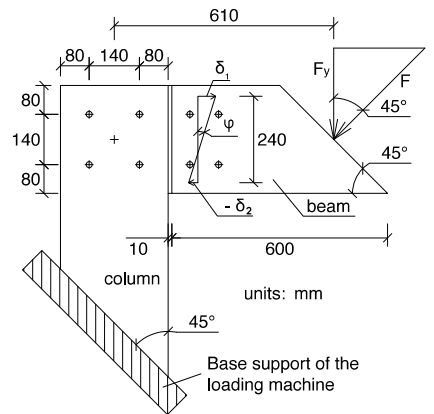

(c)

Figure 3. Experimental set-up: (a) machinery used for connection test; (b) joint under static monotonic test; and (c) graphic display of angular deformation. 


\subsection{Static Behaviour of the Joint}

The static test performed on the joint allowed to obtain the moment-rotation diagram shown in Figure 4a.

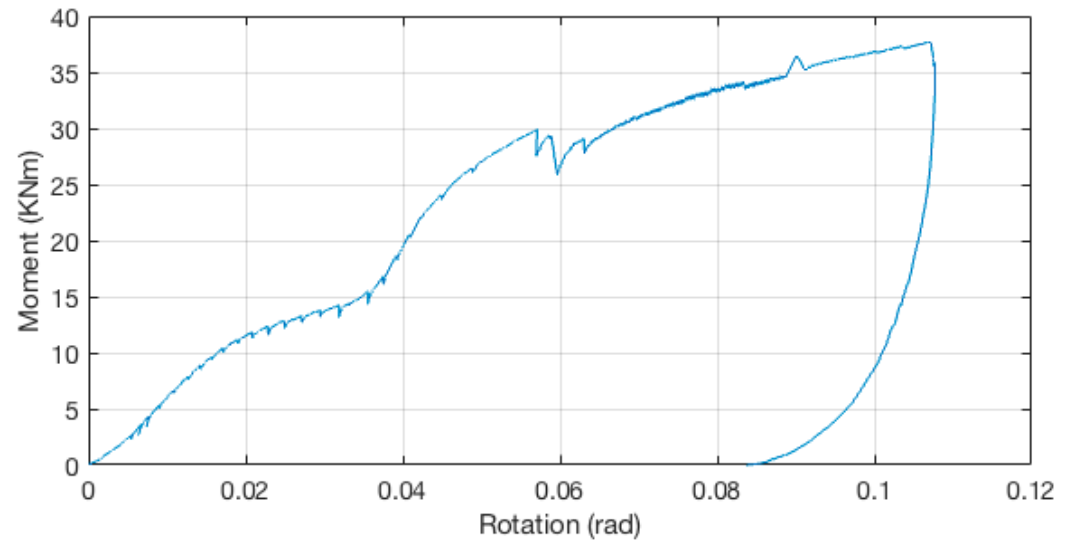

(a)

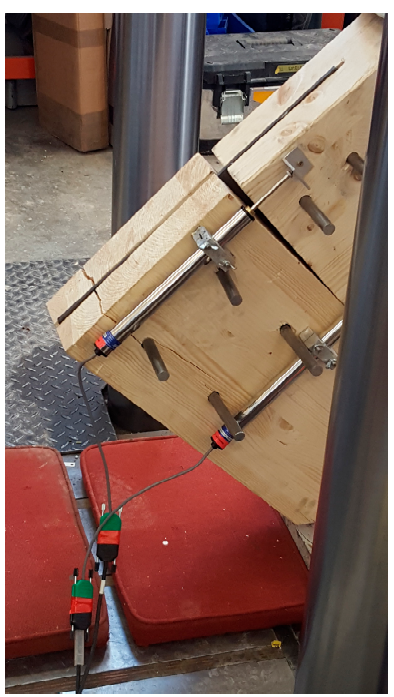

(b)

Figure 4. Connection test results: (a) moment-rotation diagram of the dowelled connection; (b) connection specimen at failure.

The examined diagram (Figure 4a) displays the whole failure load path from the beginning up to the maximum load when the cracks on the timber member become clearly visible and the test is interrupted (Figure 4b). The connection shows lower stiffness at the beginning of the loading process. Higher stiffness was not attained up to a load of $2.5 \mathrm{kNm}$. Dorn [1] argues that this initial consolidation is probably caused by imperfect contact between dowel and wood, which results from geometric roughness of the specimen in the contact zone as well as from imperfections of the contact surfaces. During the phase that directly follows the consolidation process at about $0.005 \mathrm{rad}$ (Figure 4a), the maximum stiffness of the connection is attained. Even though perfect linearity is not observed, an approximation by a straight line is possible over a short section to obtain an approximate stiffness value.

The approximate stiffness value is later used to validate the numerical model in Section 4. A 'sawtooth' path is visible since the first stages of loading path. This is supposed to be caused by invisible cracks that are occurring inside the connection since low load. When the load increases (about $11 \mathrm{kNm}$ ), the stiffness dramatically decreases and a softening behaviour is observed in the load-displacement curve. Once the moment attains a value of $15 \mathrm{kNm}$, a steep increasing of the stiffness can be seen. This atypical behaviour is because of the contact that occurred between member surfaces at bottom-side (Figure $3 b$ ). The center of rotation of both connections shifts resulting in different angles to the grain. Another non-linear path can be shown until the bending moment arrives to about $30 \mathrm{kNm}$. Here, cracking strongly occurs in part of the wood matrix that reaches the compression strength and plastic deformations. The stiffness sensitively decreases until the maximum load is attained $(37.68 \mathrm{kNm})$. A yield plateau is visible at the final stage and a maximum rotation of $0.107 \mathrm{rad}$ $\left(6.13^{\circ}\right)$ is obtained. At the end of the test, final failure occurred, resulting in a sudden load reduction (Figure 4a). Brittle failure is reached because maximum tension forces are attained perpendicular to the grain in the column member. 


\subsection{Estimation of the Rotational Stiffness of the Joint and Comparison with Eurocode Indications}

By the analysis of the first three stages of the moment-rotation relationship (Section 2.2), a linearization of the curve allows for calculating the rotational stiffness of the connection. Reynolds [7] shows that the range of loads imposed on a connection in service is of $20 \%$ and $40 \%$ of the predicted characteristic capacity. According to CEN (European Committee for Standardisation) [28] the initial stiffness is calculated from 10 to $40 \%$ of the peak load. The latter is used in this study to evaluate the rotational stiffness of the joint.

A linear regression of data in the range of $0.1 M_{\max }<M<0.4 M_{\max }$ gives the rotational stiffness,

$$
K_{\theta, \mathrm{ser}}=696 \mathrm{kNm} / \mathrm{rad}
$$

The linear fit is shown in Figure 5, where the root mean squared error is 0.191 and the correlation coefficient $\left(R^{2}\right)$ is 0.976 , suggesting a significant variation of data. This was probably due to the 'sawtooth' shape of the diagram.

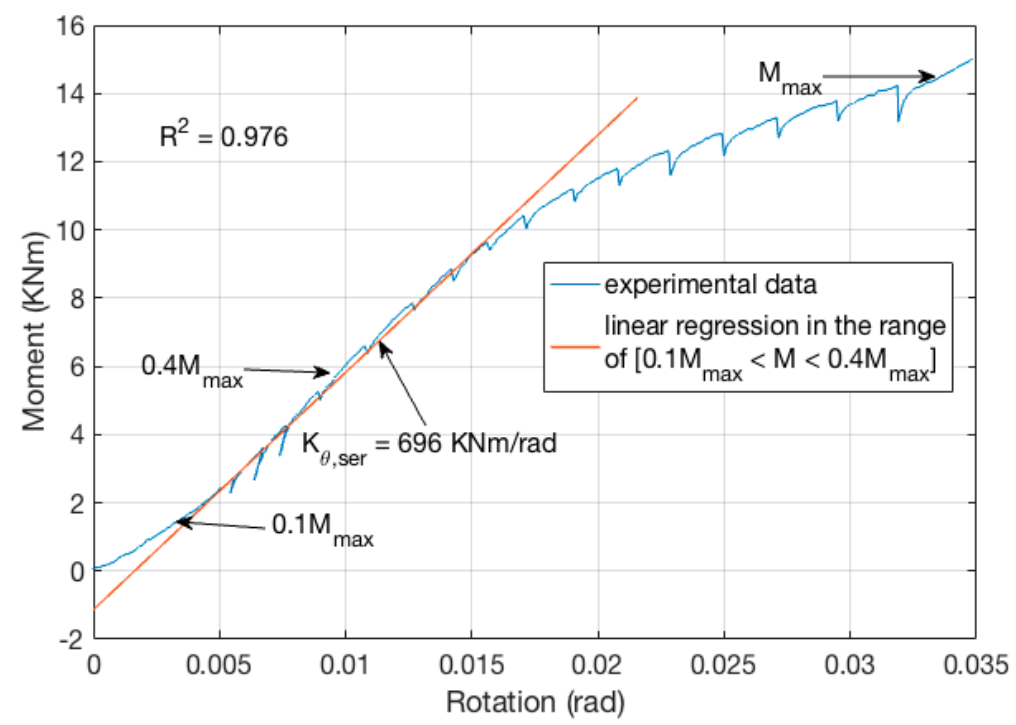

Figure 5. Linear interpolation of the moment-rotation diagram between $10 \% M_{\max }$ and $40 \% M_{\max }$.

Analytical prediction of the rotational stiffness of the connection can be done in order to compare the experimental value. Gelfi [29] evaluated the stiffness of the connection on the basis of the classical approach of the beam on elastic foundation, whereas Eurocode 5 [13] provides the analytical calculation of the slip modulus $k_{\text {ser, }}$ per shear plane, per fastener under service load, through the expression:

$$
k_{\mathrm{ser}}=2 \cdot \rho_{\mathrm{m}}^{1.5} \cdot \frac{d}{23}([13] \text { Table } 7.1)
$$

where $d$ is the diameter of the fastener and $\rho_{\mathrm{m}}$ is the mean density of timber. The stiffness can be multiplied by 2 because of the steel connector [13] (\$7.1(3)). It is straightforward to calculate the stiffness of the individual fastener as:

$$
k_{\mathrm{fas}, \mathrm{EC}}=n_{\mathrm{sp}} \cdot k_{\mathrm{ser}}
$$

where $n_{s p}$ is the number of shear plane. In this specific case,

$$
k_{\mathrm{fas}, \mathrm{EC}}=23951.1 \mathrm{kN} / \mathrm{m} \text {. }
$$


Even if $k_{\mathrm{fas}, \mathrm{EC}}$ is the serviceability limit state design value that is provided from the Eurocode, it could be of interest to extrapolate the individual fastener stiffness, $k_{\text {fas,exp }}$ from the connection rotational stiffness experimentally evaluated $\left(K_{\theta, \text { ser }}\right)$ and compare it with Eurocode design value. Because only one experiment is not enough to characterize the stiffness, comparison should be done with caution. If one assumes the joint made by two separate connections linked in series, therefore the inverse of the equivalent rotational stiffness of the connection is:

$$
\frac{1}{K_{\theta, \text { eq }}}=\frac{1}{K_{\theta, \text { col }}}+\frac{1}{K_{\theta, \text { beam }}} .
$$

where $K_{\theta \text {,col }}$ refers to the column stiffness and $K_{\theta \text {,beam }}$ to the beam one. Furthermore, each rotational stiffness can be expressed in function of the single fastener stiffness:

$$
K_{\theta}=k_{\text {fas }} \sum r_{i}^{2}
$$

where $k_{\text {fas }}$ is the stiffness value of the individual fastener (force per unit length) and $r_{i}$ is the $i$ th radius vector, namely the distance from the center of the group to the $i$ th fastener (Figure 6). By making simple calculations, in the case under examination it is:

$$
K_{\theta, \mathrm{col}}=1.508 \cdot K_{\theta, \mathrm{beam}}
$$

therefore,

$$
K_{\theta, \mathrm{col}}=1745.35 \mathrm{kNm} / \mathrm{rad}
$$

and finally,

$$
k_{\text {fas, }, \text { exp }}=\frac{K_{\theta, \text { col }}}{4 r^{2}}=44524.30 \mathrm{kN} / \mathrm{m} \text {. }
$$

The comparison of the experimentally determined stiffness with corresponding design values from EC5 leads to a ratio:

$$
\frac{k_{\mathrm{fas}, \mathrm{EC}}}{k_{\mathrm{fas}, \exp }}=0.54,
$$

graphically displayed in Figure 6.

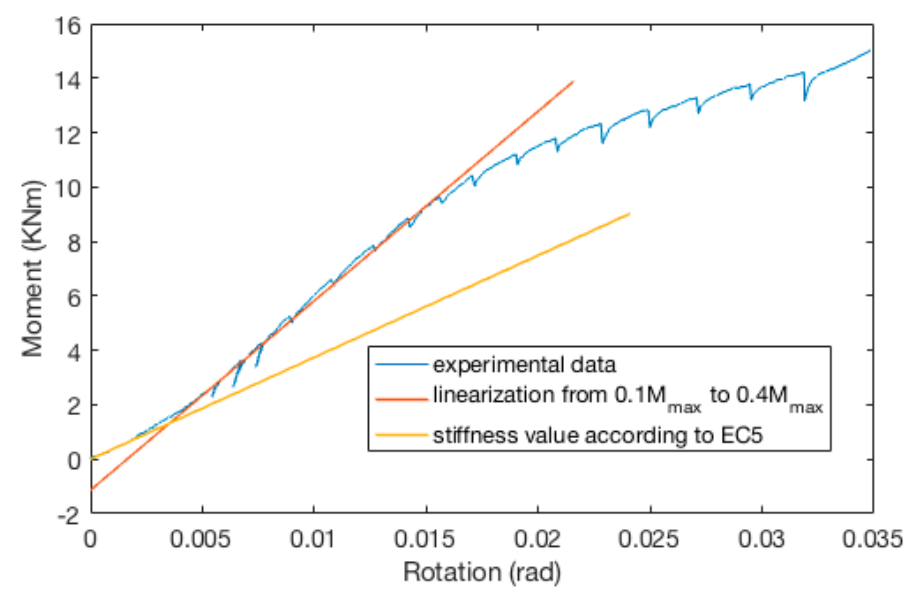

Figure 6. Comparison of experimental rotational stiffness to the Eurocode (EC) value.

The EC5 formula underestimates the stiffness, probably because it does not cover the influence of all the involved parameters, such as connection width, length of the dowel, and its consequent deformed shape. Moreover, it does not take into account the influence of the angle to grain direction and the foundation modulus. Dorn [1] compared results from dowel-type connections to the current 
generation of European standards with respect to stiffness. Results clearly show that for $200 \mathrm{~mm}$ wide specimens, the stiffness specified by EC5 underestimates the observed stiffness. Even though the first branch of the curve was assumed, the EC5 expression would have strongly underestimated the stiffness value of the joint as well.

\section{Portal Vibration Test}

\subsection{Experimental Test Set-Up}

A non-destructive vibration test was carried out to evaluate the dynamic properties (i.e., frequency and modal damping) of the timber portal frame, as shown schematically in Figure $2 \mathrm{~b}$. The portal frame is made by two identical frames with four columns and two beams all $1.5 \mathrm{~m}$ long. Description of materials, cross sections, and geometry of the joints can be found in Section 2.1. Columns are pinned at the ground through hinge-type steel-timber connections (Figure 7a,b).

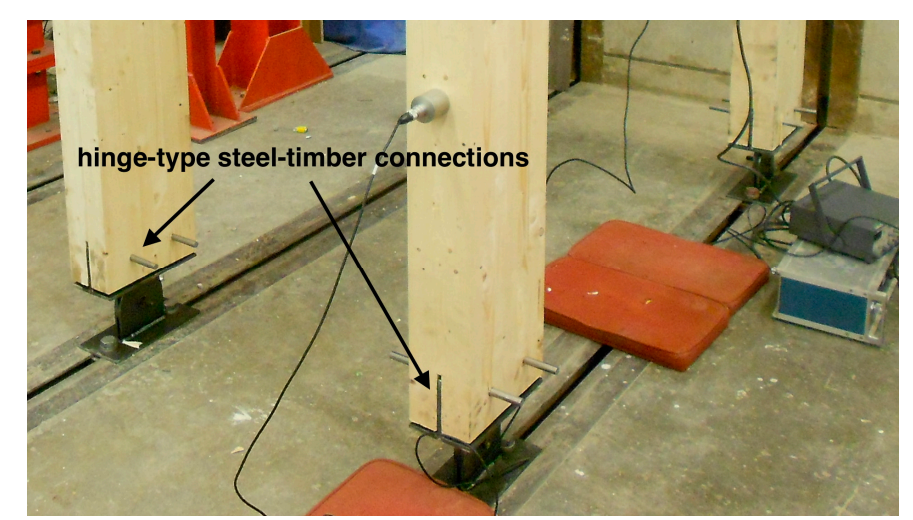

(a)

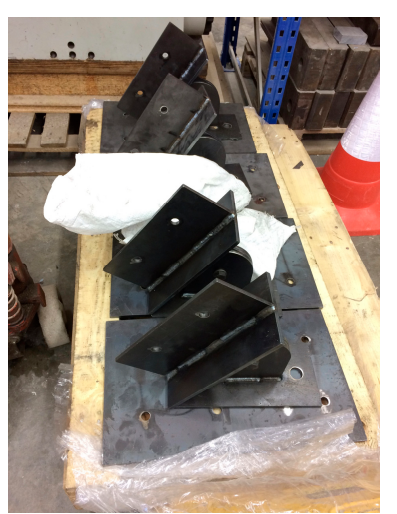

(b)

Figure 7. Details of the base connections: (a) detail of connections at the ground; (b) steel hinges.

The portal frames are connected at the top by two whitewood plywood panels, which are useful to transfer the load from the shaker to the structure, with dimensions of $1150 \mathrm{~mm} \times 600 \mathrm{~mm} \times 18 \mathrm{~mm}$.

Table 1 summarizes the main characteristics of the performed experiments. The excitation method was a slow sine sweep, in which a sinusoidal force, gradually increasing in frequency, was applied by the shaker and the rate of increase of frequency was sufficiently slow that the steady-state response at each frequency had time to develop. The shaker (APS 113 ELECTRO-SEIS ${ }^{\circledR}$, APS Dynamics, Inc., San Juan Capistrano, CA, USA) had a mass of $30 \mathrm{~kg}$ and a frequency range from 0.01 to $200 \mathrm{~Hz}$. Two piezoelectric accelerometers having a lower frequency limit of $0.1 \mathrm{~Hz}$ and a nominal sensitivity of $10 \mathrm{~V} / \mathrm{g}$ were fixed to the mid-height column (\#1, Figure $2 \mathrm{~b}$ ) and at the mid-span of the beam (\#2) to read the vertical and horizontal response (Figure 8). The data logger was connected to a laptop and the records were processed with the software LabVIEW (National Instruments, Austin, TX, USA) [30]. For all of the tests performed, a sampling rate of $500 \mathrm{~Hz}$ was used and frequency was manually tuned from $0.1 \mathrm{~Hz}$ to $100 \mathrm{~Hz}$ to cover a considerable range of frequency spectrum.

Table 1. Summary of the experimental tests performed in laboratory.

\begin{tabular}{ccccc}
\hline Test No. & Type of Specimen & Type of Test & Machine & Signal Recorded \\
\hline$\# 1$ & timber portal frame & dynamic & $\begin{array}{c}\text { shaker: APS 113 } \\
\text { ELECTRO-SEIS }\end{array}$ & accelerometer \\
\hline \multirow{2}{*}{$\# 2$} & $\begin{array}{c}\text { steel-timber } \\
\text { dowelled connection }\end{array}$ & $\begin{array}{c}\text { static } \\
\text { (displacement-control) }\end{array}$ & $\begin{array}{c}\text { Instron 2000 kN } \\
\text { Universal }\end{array}$ & displacement transducers \\
\hline
\end{tabular}




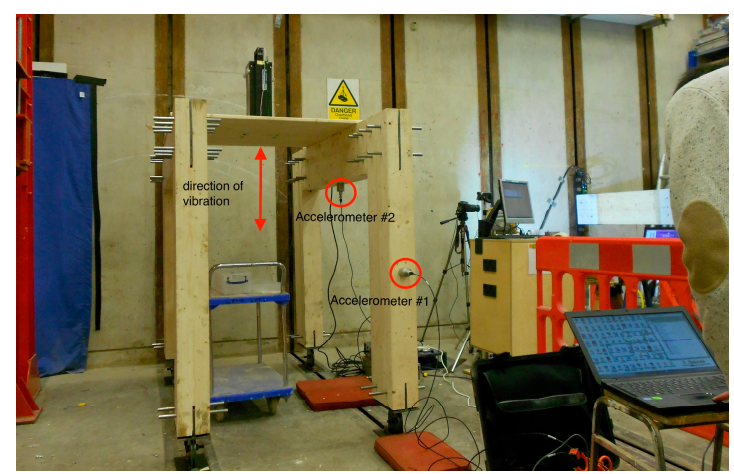

Figure 8. Portal frame under vibration test.

\subsection{Dynamic Response of the Portal Frame}

Four vibration tests (from \#1 to \#4) performed through the shaker on the portal frame provided acceleration time-histories variable with the excitation frequency. Figure 9 shows the acceleration time-histories read from both of the accelerometers during the experiments. For test \#1 and \#2, the frequency was tuned from $0.1 \mathrm{~Hz}$ to $100 \mathrm{~Hz}$, whereas, the start frequency for test \#3 and \#4 was set to $0.3 \mathrm{~Hz}$, as lower values were not significant for this case. To develop the steady-state response at each step, the frequency was manually shifted approximately every $15 \div 20 \mathrm{~s}$. Test \#2 was clearly affected from peak accelerations that were caused by instruments acting at the same time in the laboratory. Impulse-type responses were useful to evaluate free vibrations of the structure. For the third test, the rate of frequency-turning was set to $20 \mathrm{~s}$ and no relevant noise affected the signal. Finally, for the last test, a higher amplitude of the shaker was set and an accurate and clear signal was obtained.

Few seconds of free swinging of the signal were trimmed and filtered by using a bandpass filter to reduce the noise that was caused by the shaker and to extract the fundamental frequency and evaluate the damping ratio. Modal analysis of a two-dimensional (2D) numerical model of the timber frame with beam-column semi-rigid connection stiffness set at $K_{\theta}=374.4 \mathrm{kNm} / \mathrm{rad}$ (based on the slip modulus, $k_{\text {ser }}$ from EC5 [13]) was performed to evaluate the natural frequency of the structure corresponding to the interesting mode of vibration (i.e., horizontal swinging):

$$
f_{\text {mod }}=14.23 \mathrm{~Hz}
$$

Thus, the natural frequency of the portal frame is assumed to be included in the range $6 \mathrm{~Hz} \div 30 \mathrm{~Hz}$.
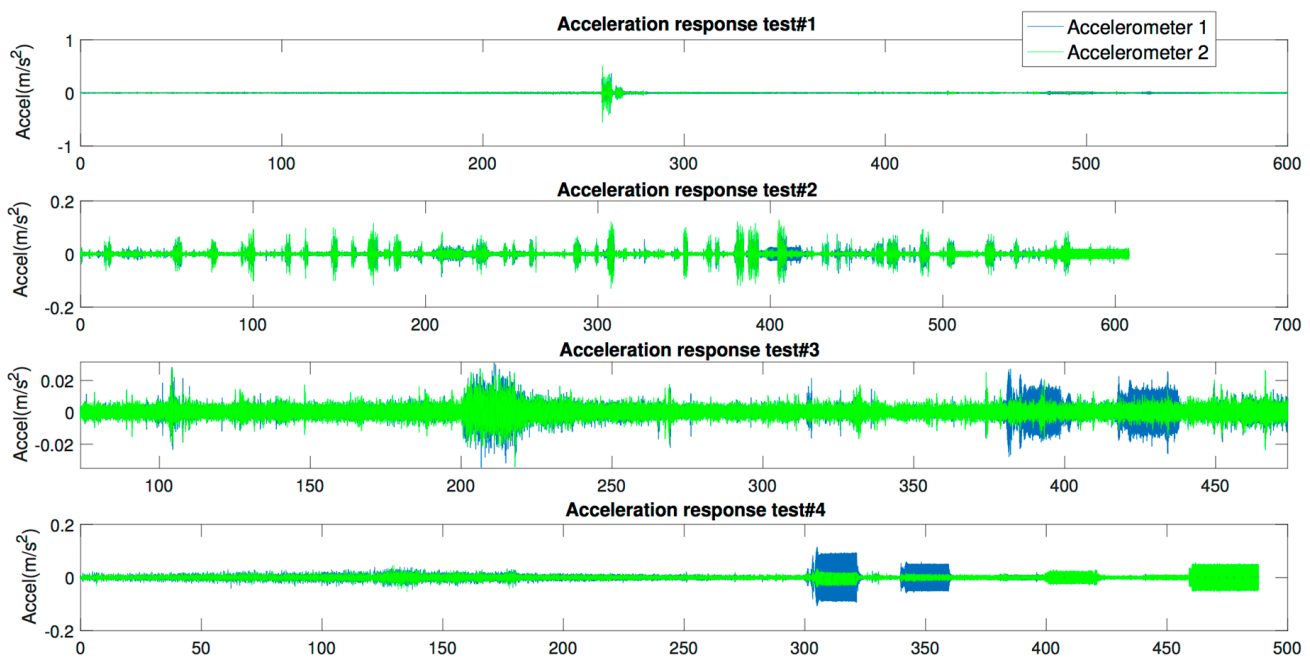

Figure 9. Registered acceleration time-histories of the four tests (time in s). 
A 9th-order Butterworth filter was chosen to eliminate frequencies outside the interesting range. Figure 10 shows the filtered time history record of one of the trimmed signal $(106.80<T<107.70)$ from test \#2 displayed in Figure 11.

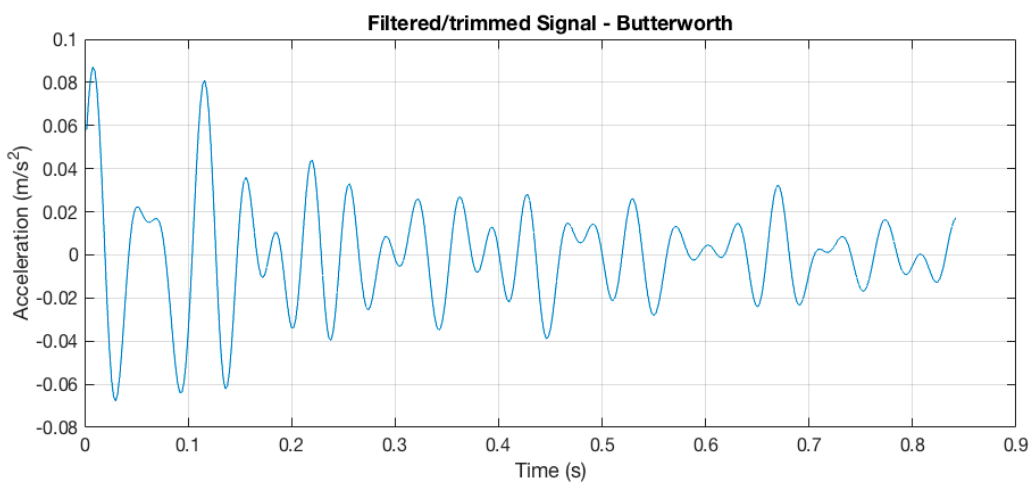

Figure 10. Filtered signal using a 9th-order Butterworth filter.

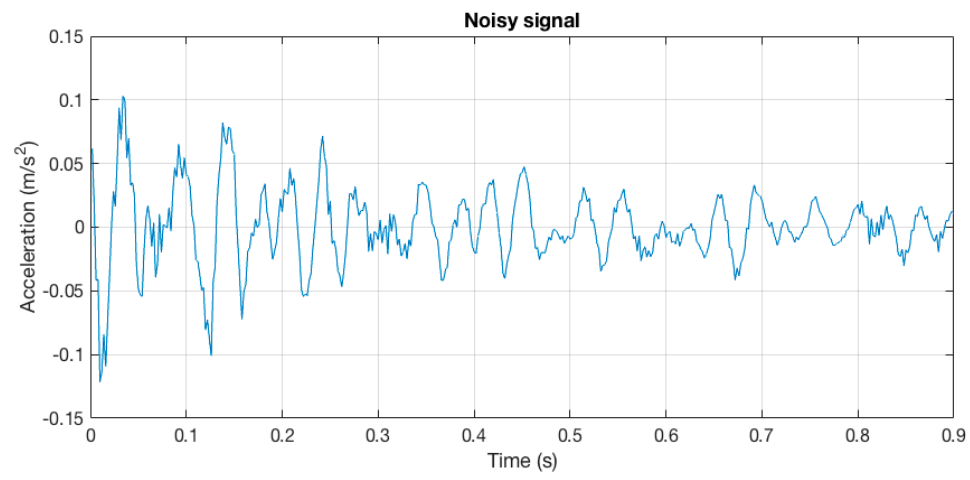

Figure 11. Trimmed signal, $T=0.9 \mathrm{~s}$, test \#2, accelerometer \#1 (column mid-height).

\subsection{Signal Curve Fitting Process}

The acceleration time histories data (obtained as illustrated in Section 3.2) are processed in time domain by using the Matrix Pencil Algorithm (MP Algorithm) [4] through a specifically developed MATLAB script, where the number of modes contributing to vibration signal has to be assumed. A wrong assumption could lead to misleading results of the damping ratios. The algorithm derives fundamental frequencies and associated damping ratios, and performs a procedure to compare fitted signal to the measured signal visually, as shown in Figure 12. A very good agreement is obtained.

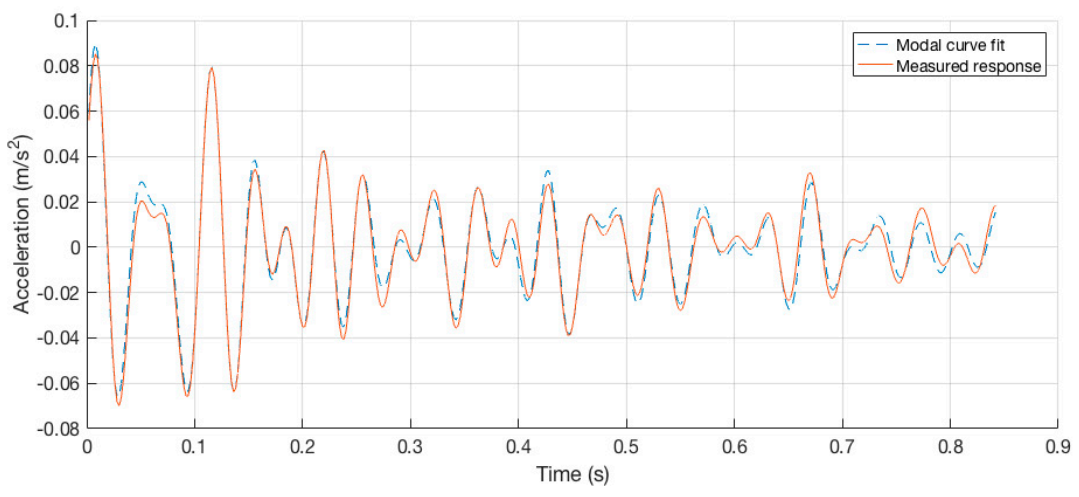

Figure 12. Modal curvefitting of the signal. 
Table 2 collects all of the analysis results and shows for each analyzed segment the relative frequency and the corresponding damping ratio of the whole structure, as found from curve fitting. $T_{1}$ and $T_{2}$ are the lower and the upper limits of the segment analyzed. Most of the segments are chosen from the second test (\#2, Figure 9) where free vibrations are visible. Many analyses are performed in the range of $405-409 \mathrm{~s}$ where resonance is clear. The average frequency is calculated with the following:

$$
f_{\text {mean }}=\frac{1}{10} \sum_{i} f_{\mathrm{i}}=19.48 \mathrm{~Hz}
$$

To evaluate the precision of the observed data, the standard deviation is evaluated:

$$
\sigma=\sqrt{\frac{1}{10} \sum_{i}\left(f_{\mathrm{i}}-f_{\text {mean }}\right)^{2}}=0.6734
$$

showing an acceptable accuracy of the analysis. The dispersion is shown in Figure 13.

Table 2. Curvefitting experimental signal.

\begin{tabular}{ccccc}
\hline Analysis & Test & $\boldsymbol{T}_{\mathbf{1}}<\boldsymbol{T}<\boldsymbol{T}_{\mathbf{2}}$ & $\boldsymbol{f}$ & $\boldsymbol{\xi}$ \\
\hline No. & $\#$ & $(\mathbf{s})$ & $(\mathbf{H z})$ & $\mathbf{( \% )}$ \\
\hline 1 & 2 & $52.54<T<53.50$ & 19.08 & 0.82 \\
2 & 2 & $106.80<T<107.70$ & 19.44 & 1.45 \\
3 & 1 & $264.40<T<265.40$ & 19.22 & 4.18 \\
4 & 2 & $309.70<T<310.00$ & 18.29 & 2.86 \\
5 & 2 & $409.30<T<409.50$ & 19.90 & 1.40 \\
6 & 2 & $416.85<T<417.10$ & 20.27 & 3.83 \\
7 & 2 & $405.00<T<405.14$ & 20.71 & 0.50 \\
8 & 2 & $406.20<T<406.50$ & 19.23 & 0.62 \\
9 & 2 & $407.40<T<407.80$ & 19.28 & 1.12 \\
10 & 2 & $409.30<T<409.50$ & 19.34 & 0.32 \\
\hline
\end{tabular}

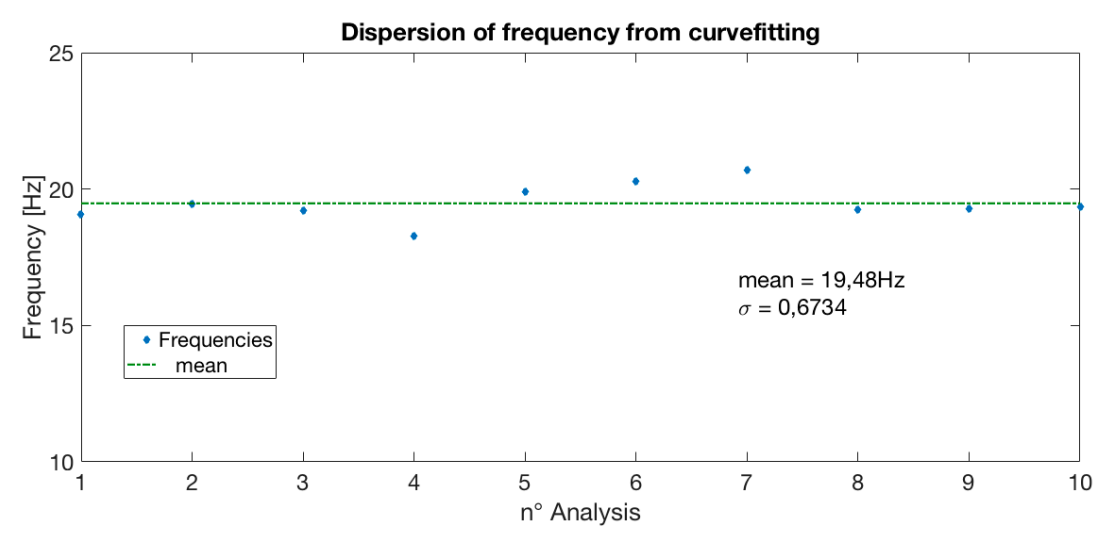

Figure 13. Dispersion of data.

\section{Numerical Model of the Portal Frame}

\section{Modelling and Analysis}

The 3D portal frame is modelled in OpenSees [27]; it includes 156 nodes and 148 elements, of frame-type elastic and isotropic (Figure 14a). The material used for modelling glulam timber is graded GL-24h according to EN 14080 [28], whose mechanical properties are listed in Table 3. Density was experimentally measured and a value of $\rho=352 \frac{\mathrm{kg}}{\mathrm{m}^{3}}$ was obtained. 


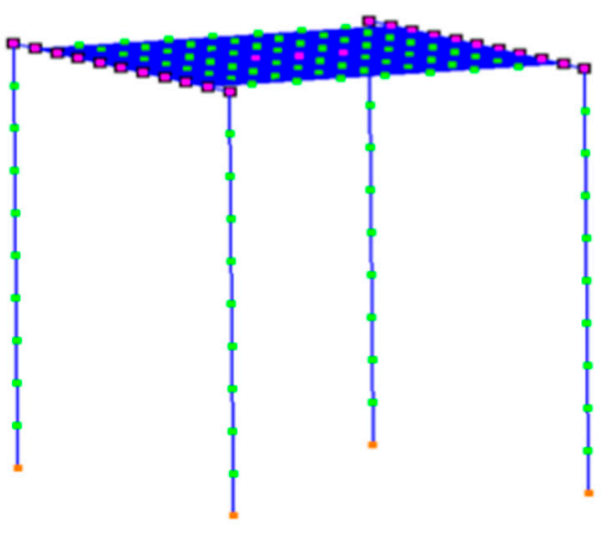

(a)

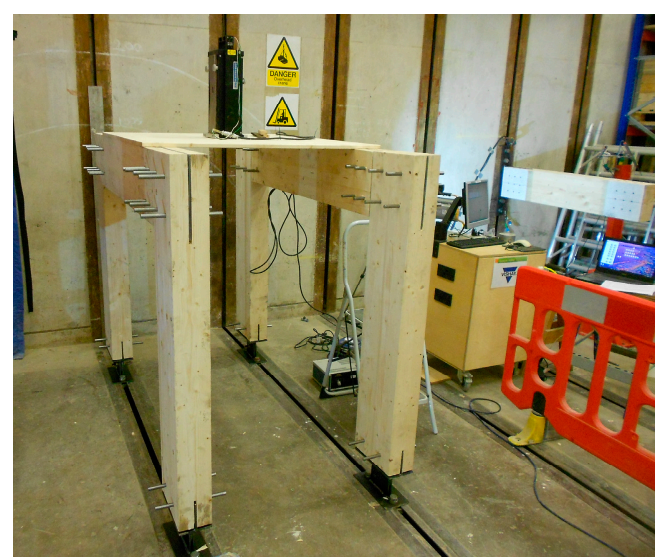

(b)

Figure 14. (a) OpenSees numerical model; (b) portal frame under vertical vibration.

Table 3. Properties of GL 24h according to EN 14080:2013 [28] assumed in the numerical simulation.

\begin{tabular}{ccc}
\hline & $E_{0, \mathrm{~g}, \text { mean }}$ & $G_{0, \text { g,mean }}$ \\
\hline Class & $\left(\mathbf{N} / \mathbf{m m}^{2}\right)$ & $\left(\mathbf{N} / \mathbf{m m}^{2}\right)$ \\
GL 24h & 11,500 & 600 \\
\hline
\end{tabular}

The horizontal panels that are placed at the top of the frame are modelled as shells, meshed with elastic orthotropic nDmaterial $18 \mathrm{~mm}$-thick. The beam length is set to $1.32 \mathrm{~m}$ to take into account the dimension of the connections in both sides. Columns are $1.35 \mathrm{~m}$ long and the distance between the two frames is $1.10 \mathrm{~m}$. All of the support nodes are pinned at the base. Rotational springs simulate the connection between beam and column and between slab panel and beam. The numerical simulation neglects the strengthening effect of the panel with respect to the beams as nailed at the top of the elements. Modal analysis has been done to evaluate eigenmodes and corresponding eigenfrequencies. The response of the portal frame model is validated by assuming the value of rotational stiffness resulted from experimental test $\left(K_{\theta, \mathrm{ser}}\right)$. Moreover, the stiffness value of the connections $K_{\theta, \mathrm{EC}}$, based on the Eurocode 5 and evaluated in Section 2.3 is also set and results are compared. Further analytical models $[6,31]$ can be used in order to predict the initial rotational stiffness of the joint based on the mechanical properties of the elements and on the geometry. These models are usually based on the classical approach of the beam on elastic foundation but are not considered in this work.

The modal analysis outcomes are reported in Table 4, where $f$ is the natural frequency, corresponding to the direction along beam-column connections.

Table 4. Results from modal analysis for the three-dimensional (3D) portal frame model.

\begin{tabular}{ccc}
\hline Rotational Stiffness & Value $(\mathbf{K N m} / \mathbf{r a d})$ & $f(\mathbf{H z})$ \\
\hline$K_{\theta, \mathrm{ser}}$ & 696.0 & 17.84 \\
$K_{\theta, \mathrm{EC}}$ & 374.4 & 13.06 \\
\hline
\end{tabular}

Figure 15 shows the third mode shape when $K_{\theta}=K_{\theta, \text { ser }}$, namely when the second branch of the moment-rotation relationship is assumed for the stiffness calculation (Section 2.3). The percentage difference between the experimental and numerical eigenfrequencies is $8.2 \%$; their ratio is 1.09 , value considered acceptable for the uncertainties, that, in any case, affect a numerical model.

As discussed in the Introduction, localized phenomena at the connection level have been evaluated by testing a full scale specimen, whereas the global elastic characteristics have been obtained through a scaled model (1:2). Anyway, to evaluate the scale effect, it could be worthy to vary the dimensions in 
the validated FE model. By doubling the length of the structural members, the eigenfrequency of the prototype is about half of that of the model:

$$
f=8.48 \mathrm{~Hz}
$$

Other scale effects can be considered in further studies by varying the dimensions of the connectors and keeping their geometry constant. One of the limitations of this work is that the investigation only considers the linear-elastic behaviour of the dowel connections neglecting their cyclic hysteretic behavior, necessary to assess damping and dissipation of energy.

Further studies will be addressed to find a simple and efficient analytical model that is useful to represent a wide range of connections as a function of geometry and mechanical properties of the components. These models can be applied in numerical models of timber buildings to better evaluate the influence of connections on the building dynamic behaviour.

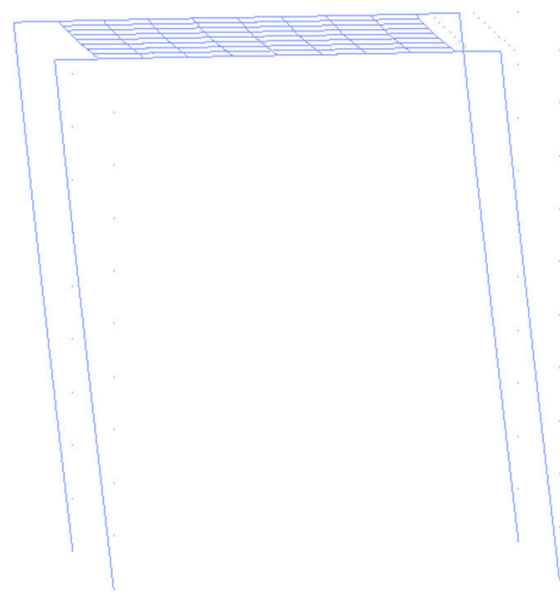

Figure 15. Third mode shape of portal frame 3D model, $f=17.84 \mathrm{~Hz}$.

\section{Conclusions}

This work investigated the interaction between steel and timber in dowel-type connections, in the experimental and numerical perspective.

Laboratory tests on portal frame and connections allowed for the evaluation of the single fastener shear stiffness. The results of the experimental tests showed rotational stiffness values that were overestimated by about two times with respect to the Eurocode indications. Through a curve-fitting method, the experimental results in terms of acceleration time-histories were filtered up and the resonance condition gave the relevant frequency of vibration of the portal frame. The modal analysis was performed on a 3D portal frame by setting the rotational joint stiffness that was calculated when considering the linearization in the range of $0.1 M_{\max }<M<0.4 M_{\max }$ of the moment-rotation relationship obtained from the experimental test. The experimental frequency was seen to be less than $10 \%$ higher than the eigenfrequency obtained through the modal analysis. The results are then in good mutual agreement; the percentage difference of $8.4 \%$ is probably due to the uncertainties of the actual timber mechanical properties and on the strengthening effect of the horizontal panel nailed at the top of the frame.

This work only considers the linear-elastic behaviour of the dowel connections without taking into account the cyclic hysteretic loop of the joints, which is useful to assess the damping and dissipation of energy.

Further studies will be addressed to find a simple and efficient analytical model useful to represent a wide range of connections as a function of geometry and mechanical properties of the components. 
Author Contributions: Wen-Shao Chang and Haoyu Huang conceived and designed the experiments; Fabio Solarino, Haoyu Huang and Linda Giresini performed the experiments; Fabio Solarino and Linda Giresini analyzed the data; Wen-Shao Chang contributed materials/analysis tools. All authors contributed to write the paper.

Conflicts of Interest: The authors declare no conflict of interest.

\section{References}

1. Dorn, M.; de Borst, K.; Eberhardsteiner, J. Experiments on dowel-type timber connections. Eng. Struct. 2013, 47,67-80. [CrossRef]

2. Sawata, K.; Sasaki, T.; Kanetaka, S. Estimation of shear strength of dowel-type timber connections with multiple slotted-in steel plates by European yield theory. J. Wood Sci. 2006, 52, 496-502. [CrossRef]

3. Polastri, A.; Tomasi, R.; Piazza, M.; Smith, I. Moment resisting dowelled joints in timber structures: Mechanical behaviour under cyclic tests. Ing. Sismica 2013, 30, 72-81.

4. Bouchaïr, A.; Racher, P.; Bocquet, J.F. Analysis of dowelled timber to timber moment-resisting joints. Mater. Struct. 2007, 40, 1127-1141. [CrossRef]

5. Chui, Y.H.; Li, Y. Modeling Timber Moment Connection under Reversed Cyclic Loading. J. Struct. Eng. 2005, 131, 1757-1763. [CrossRef]

6. Reynolds, T.; Harris, R.; Chang, W.S. Dynamic stiffness and damping of dowel-type connections for timber structures under service conditions. In World Conference on Timber Engineering 2012 (WCTE 2012): Auckland, New Zealand, 15-19 July 2012; New Zealand Timber Design Society: Auckland, New Zealand, 2012; Volume 1, pp. 566-573.

7. Reynolds, T.; Harris, R.; Chang, W.S. In-Service Dynamic Stiffness of Dowel-Type Connections. In Proceedings of the CIB-W18 on Timber Structures, Vancouver, BC, Canada, 26-29 August 2013.

8. De Jong, T. Stresses Around Pin-Loaded Holes in Elastically Orthotropic or Isotropic Plates. J. Compos. Mater. 1977, 11, 313-331. [CrossRef]

9. Zhang, K.-d.; Ueng, C.E.S. Stresses around a pin-loaded hole in orthotropic plates with arbitrary loading direction. Compos. Struct. 1985, 3, 119-143. [CrossRef]

10. Hyer, M.W.; Klang, E.C. Contact stresses in pin-loaded orthotropic plates. Int. J. Solids Struct. 1985, 21, 957-975. [CrossRef]

11. Echavarría, C.; Haller, P.; Salenikovich, A. Analytical study of a pin-loaded hole in elastic orthotropic plates. Compos. Struct. 2007, 79, 107-112. [CrossRef]

12. Lekhnitskii, S.G. Anisotropic Plates; Gordon and Breach Science Publisher: New York, NY, USA, 1968.

13. Uni En BS. EN 1995-1-1:2004-Eurocode 5: Design of timber structures—Part 1-1: General—Common rules and rules for buildings. Eurocode 5 2004, 1, 1-123.

14. Casapulla, C.; Argiento, L.U. The comparative role of friction in local out-of-plane mechanisms of masonry buildings. Pushover analysis and experimental investigation. Eng. Struct. 2016, 126, 158-173. [CrossRef]

15. Casapulla, C.; Portioli, F. Experimental tests on the limit states of dry-jointed tuff blocks. Mater. Struct. Constr. 2016, 49, 751-767. [CrossRef]

16. Casapulla, C.; Argiento, L.U. In-plane frictional resistances in dry block masonry walls and rocking-sliding failure modes revisited and experimentally validated-Under review. Compos. Part B Eng. 2018, 132, 197-213. [CrossRef]

17. Andreini, M.; De Falco, A.; Giresini, L.; Sassu, M. Structural analysis and consolidation strategy of the historic Mediceo Aqueduct in Pisa (Italy). Appl. Mech. Mater. 2013, 351-352, 1354-1357. [CrossRef]

18. Casapulla, C.; Jossa, P.; Maione, A. Rocking motion of a masonry rigid block under seismic actions: A new strategy based on the progressive correction of the resonance response I Il moto sotto sisma del blocco murario: Analisi per progressiva correzione della risposta in risonanza. Ing. Sismica 2010, 27, 35-48.

19. Casapulla, C. On the resonance conditions of rigid rocking blocks. Int. J. Eng. Technol. 2015, 7, 760-771.

20. Ceccotti, A.; Vignoli, A. A hysteretic behavioural model for semirigid joints. Eur. Earthq. Eng. 1989, 3, 3-9.

21. Foschi, R.O. Modelling the Hysteretic Response of Mechanical Connections for Wood Structures. Available online: http:/ / timber.ce.wsu.edu/resources / papers/7-1-2.pdf (accessed on 9 August 2017).

22. Wong, E.Y. Verification of an Analytical Hysteresis Model for Dowel-Type Timber Connections Using Shake Table Tests; University of British Columbia: Vancuver, BC, Canada, 1999. 
23. Chui, Y.H.; Ni, C.; Jiang, L. Finite-Element Model for Nailed Wood Joints under Reversed Cyclic Load. J. Struct. Eng. ASCE 1998, 124, 96-103. [CrossRef]

24. Krawinkler, H. Scale effects in static and dynamic model testing of structures. In Proceedings of the Ninth World Conference on Earthquake Engineering, Tokyo, Japan, 2-9 August 1988; pp. 865-876.

25. MathWorks. Matlab R2016b; MathWorks: Natick, MA, USA, 2016.

26. Sarkar, T.K.; Pereira, O. Using the Matrix Pencil Method to Estimate the Parameters of a Sum of Complex Exponentials. IEEE Antennas Propag. Mag. 1995, 37, 48-55. [CrossRef]

27. Pacific Earthquake Engineering Research Center (PEER). OpenSees: Open System For Earthquake Engineering Simulation; PEER: Berkeley, CA, USA, 2006.

28. Internetional Organization for Standardization (ISO). EN 14080:2013 Timber Structures—Glued Laminated Timber (GLT) and Cross Laminated Timber (CLT)—Requirements 2013; ISO: Geneva, Switzerland, 2013.

29. Muñoz, W.; Mohammad, M.; Salenikovich, A.; Quenneville, P. Yield point and ductility of timber assemblies: A need for a harmonised approach. Proc. Annu. Conf. Can. Soc. Civ. Eng. 2008, 2, 1146-1155.

30. National Instruments (NI). LabVIEW; National Instruments: Austin, TX, USA, 2012.

31. Gelfi, P.; Giuriani, E.; Marini, A. Stud Shear Connection Design for Composite Concrete Slab and Wood Beams. J. Struct. Eng. 2002, 128, 1544-1550. [CrossRef]

(c) 2017 by the authors. Licensee MDPI, Basel, Switzerland. This article is an open access article distributed under the terms and conditions of the Creative Commons Attribution (CC BY) license (http:// creativecommons.org/licenses/by/4.0/). 